\title{
Magnetic Zeolite-Polymer Composite as an Adsorbent for the Remediation of Wastewaters Containing Vanadium
}

\author{
Nomcebo H. Mthombeni, Sandrine Mbakop, and Maurice S. Onyango
}

\begin{abstract}
Magnetic natural zeolite-polypyrrole composite was prepared for removal of vanadium from aqueous solution. The effects of initial $\mathrm{pH}$, sorbent dosage, adsorption isotherms on removal efficiency were investigated. Up to $75 \%$ removal efficiency was obtained when the $\mathrm{pH}$ was 5 and the initial vanadium concentration was $100 \mathrm{mg} / \mathrm{L}$. The isotherm data fitted well to the Langmuir isotherm model. The maximum adsorption capacity determined from the Langmuir isotherm was $57.803 \mathrm{mg} / \mathrm{g}$ at $25^{\circ} \mathrm{C}$.
\end{abstract}

Index Terms-Vanadium, magnetic, zeolite, adsorption.

\section{INTRODUCTION}

The presence of heavy metals ions in water bodies is becoming a serious threat to public health and the environment. Of these heavy metals, vanadium has recently received more attention because of its adverse effect on human health and the environment. At high concentration vanadium is an environmentally harmful substance and causes diverse toxic effects on humans such as anaemia, cough, emaciation, and irritation of mucous membrane, gastrointestinal disturbances, and bronchopneumonia [1], [2] .

Treatment processes for vanadium contaminated waste streams include chemical precipitation, filtration, ion exchange [3], reverse osmosis, solvent extraction [4] electro-deposition adsorption and biological methods [5] among others. Due to limitations in terms of equipment cost and space requirement, incomplete metals removal, massive waste generation and high reagent consumption of some of these methods, adsorption is the most commonly used technique in industries where large volumes of waste effluents are generated. Adsorption is a simple, low-cost, rapid, versatile and non-hazardous purification method that facilitates the recovery of treated metals for reuse [6].

Since the choice of the sorbent material for any adsorption process is important and depends on its cost, availability and suitability to remove the given pollutant; scattered studies have been conducted for the past years to develop adsorbents mainly from several agricultural and industrial waste materials with the dual aim of low cost as well as

Manuscript received August 15, 2014; revised November 4, 2014. This work was supported by National Research Foundation (South Africa), University of South Africa and Tshwane University of Technology.

The authors are with the Tshwane University of Technology, Private Bag X680, 0001, Staatsartillerie, Pretoria West South Africa (e-mail: nomceboh@tut.ac.za, onyangoms@tut.ac.za). effectiveness for adsorption process optimization [5].

Materials such as $\mathrm{ZnCl}_{2}$ active carbon [7], alumina, metal sludge [8], goethite [9], hydrotalcite [10] crystalline hydroxyl apatite, amine-functionalized - grafted tamarind fruits hell [2], chitosan [6], [11], persimmon tannin gel [12] and metal hydroxide [1] have been used as adsorbents for removal of vanadium (V) from aqueous solution. Because of its sorption capacity for numerous pollutants, its abundance and relatively low cost; clinoptilolite has been recognized as an efficient adsorbent for a large number of water treatment applications including removal of heavy metals form industrial wastewaters. However the diffusion restrictions (specially within macromolecules) causing low sorption capacity and kinetics, the difficulties of separation from wastewater or the generation of secondary wastes, the high cost and limited active surface sites of these conventional adsorbents represent a major drawback to this separation technology. Therefore it is important to develop novel material that will overcome these limitations.

Nanotechnology has been regarded as a powerful platform for the 21 st century technologies. The application of nanoadsorbents in wastewaters treatment has gained interest in recent years. Due to their high their exceptionally large surface area, active sites and short diffusion length resulting in high sorption capacity and fast kinetics nanomaterials provide the opportunity to solve several environmental issues including water quality [13]. Among existing nanoadsorbents, magnetic nanocomposites have been extensively investigated and have been reported to offer optimum adsorption processes. This is because; unlike traditional nanoadsorbents they are easily separated and recovered from aqueous solutions [14].

Magnetic nanocomposites are often composed of magnetic nanoparticles dispersed in a polymer matrix including natural and synthetic polymers. Recently polypyrrole has increasingly received more attention due to its relatively good environmental stability, low-cost, ease of preparation and nontoxicity which are favorable for various types of applications. Different studies have revealed the effectiveness of adsorptive removal of heavy metal ions using magnetite-polypyrrole nanocomposite as sorbent media [15].

This study seeks to synthesize magnetic zeolite-polypyrrole and assess its application in adsorptive of vanadium from synthetic wastewater. There is very limited research on the application of nano-scale sorbents to remove vanadium from aqueous solutions. Moreover, there is rarely any information on the application of this technique in South Africa. Consequently in this work a technique combining adsorption and nanotechnology is proposed in order to provide an alternative technology for improved removal of 
vanadium from wastewaters.

\section{MATERIALS AND METHOD}

\section{A. Synthesis of an Adsorbent}

Magnetic zeolite was prepared by chemical co-precipitation of $\mathrm{Fe}^{3+}$ and $\mathrm{Fe}^{2+}$ ions at a ratio of $2: 1$ in the presence of zeolite [12]. The $\mathrm{Fe}^{3+} / \mathrm{Fe}^{2+}$ solution was added drop wise to the vigorously stirred mixture of zeolite and sodium hydroxide maintained at $95^{\circ} \mathrm{C}$ under $\mathrm{N}_{2}$ atmosphere. This generated the formation of a black precipitate of magnetic zeolite. The reaction was carried out for an additional hour under the nitrogen environment. The obtained magnetic zeolite powder was washed repeatedly with deionized water until a neutral $\mathrm{pH}$ was attained. Then resulting magnetic zeolite was dried under vacuum for 12 hours.

Magnetic zeolite polypyrrole nanocomposite was synthesized using in situ chemical oxidative polymerization method [8]. A known amount of magnetic zeolite powder was dispersed by adding $80 \mathrm{~mL}$ of deionized water and the mixture was placed under ultrasonication for 20 minutes. Pyrrole monomer was syringed into the mixture then hand shaken thoroughly for 5 minutes. The polymerisation process was facilitated by adding $6 \mathrm{~g}$ of anhydrous ferric chloride to the mixture while shaking therefore, forming a pitch black precipitate of magnetic zeolite-polypyrrole nanocomposite. The mixture was shaken for $3 \mathrm{~h}$ at room temperature to allow the polymerization to go into completion. Afterwards, the precipitated magnetic zeolite polypyrrole nanocomposite was vacuum filtered and thoroughly rinsed with distilled water and acetone to sterilize the material and stop the polymerization process. The synthesized powder was dried at $80^{\circ} \mathrm{C}$ for 6 hours.

\section{B. Batch Adsorption Studies}

Adsorption performance of the synthesized magnetic zeolite-polypyrrole composite was studied by batch technique. Initially, the optimum $\mathrm{pH}$ for the adsorption of vanadium onto the nanocomposite was determined by studying the effect of solution $\mathrm{pH}$ on the process. The initial $\mathrm{pH}$ was adjusted from 2 to 10 by using either $0.1 \mathrm{M}$ of hydrochloric acid or $0.1 \mathrm{M}$ of sodium hydroxide; then $0.1 \mathrm{~g}$ of magnetic zeolite-polypyrrole nanocomposite was added to $100 \mathrm{~mL}$ sample bottles containing $50 \mathrm{~mL}$ solution of vanadium with a concentration of $100 \mathrm{ppm}$. The bottles were placed in a thermostatic shaker 24 hours. The samples were analyzed by Inductively Couple Plasma- Emission Spectroscopy (ICP-OES) to determine the residual vanadium concentration. Once the solution $\mathrm{pH}$ for optimum adsorption was determined; the synthetic vanadium aqueous solution $\mathrm{pH}$ was adjusted to this optimum value and the above procedure was repeated to evaluate the effect of the remaining parameters. The effect of adsorbent mass on the amount of vanadium removed was explored by varying the mass of the sorbent material from 0.01 to $0.2 \mathrm{~g}$ whereas the effect of initial ion concentration was assessed by varying the concentration of vanadium aqueous solution from $100 \mathrm{ppm}$ to $800 \mathrm{ppm}$. Finally the adsorption isotherm was explored using vanadium solutions of concentrations ranging from $100 \mathrm{ppm}$ to $800 \mathrm{ppm}$ at temperature of $25^{\circ} \mathrm{C}$. The percentage removal of vanadium was calculated using the formula:

$$
\% \text { removal }=\frac{C_{o}-C_{e}}{C_{o}} \times 100
$$

where $C_{o}(\mathrm{mg} / \mathrm{L})$ is the initial vanadium concentration and $C_{e}$ $(\mathrm{mg} / \mathrm{L})$ is the concentration of vanadium at equilibrium.

\section{RESUlts}

\section{A. Effect of $p H$}

The initial $\mathrm{pH}$ of the solution is one of the most significant parameters in adsorption experiments. The initial solution $\mathrm{pH}$ ranged from 2-8 for an initial concentration of $100 \mathrm{ppm}$ at a temperature of $298 \mathrm{~K}$. Fig. 1 shows the sorption ability of the composite at different $\mathrm{pH}$ values. From the plot, the results shows that vanadium removal is $\mathrm{pH}$-dependent and that maximum removal occurs between at $\mathrm{pH}$ 4-5.

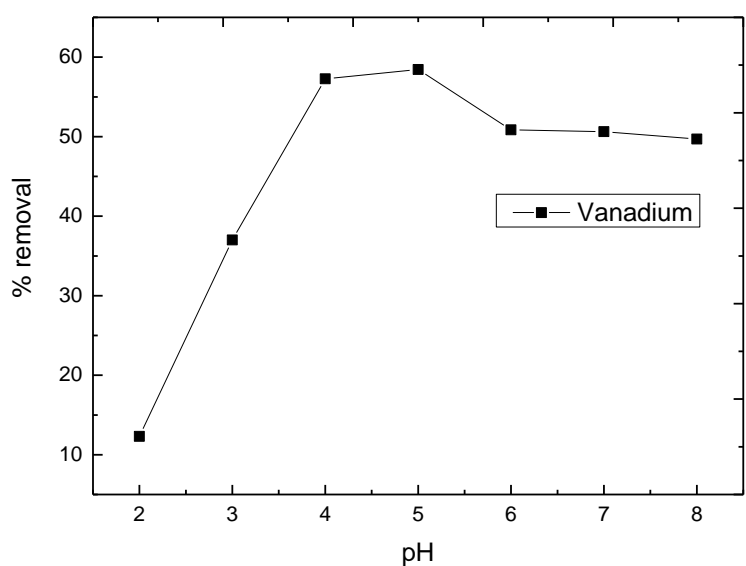

Fig. 1. Effect of initial solution $\mathrm{pH}$ on vanadium adsorption onto magnetic zeolite polypyrrole (Temp. 298K, initial conc. $100 \mathrm{ppm}$, sorbent mass $0.1 \mathrm{~g}$, duration $24 \mathrm{~h}$ ).

The adsorption effectiveness different initial solution $\mathrm{pH}$ of $\mathrm{V}(\mathrm{V})$ is greatly related to the speciation of $\mathrm{V}(\mathrm{V})$ in aqueous solution as well as the surface characteristics of the composite. The decrease removal efficiencies below $\mathrm{pH} 3.0$ might be due to the existence of $\mathrm{VO}_{2}{ }^{+}$ion, which experiences electrostatic repulsion from the protonated amino groups of the adsorbent [2], [6]. The composite and sorbate properties could be used to understand these observations. By increasing the solution $\mathrm{pH}$, the magnetite surface was deprotonated and its exchange capacity increased [16]. The decrease of amount of vanadium removed between the $\mathrm{pH}$ range of 6-9 could be explain by the polymerization ability of vanadium at various $\mathrm{pH}$. Crans [17] reported that vanadium forms polymeric species on a variation of $\mathrm{pH}$. The presence of polymeric species could limit the removal efficiency of vanadium species even at optimum $\mathrm{pH}$ especially when high concentration of vanadium is involved. Moreover, the chemistry of vanadium (V) in aqueous solution is complex [18].

\section{B. Effect of Adsorbent Mass}

The effect of sorbent mass on the remediation efficiency of the synthetic vanadium aqueous solution was explored at temperature $298 \mathrm{~K}$, with sorbent dose between 0.025-0.2 g and an initial pH of 5. Fig. 2 illustrates the effect of adsorbent 
mass on vanadium removal efficiency. The optimum adsorbent dosage was found to be at $0.15 \mathrm{~g}$. The amount of vanadium adsorbed increases with increasing sorbent dosage. This could be the result of more available active sites for vanadium sorption which directly proportional to the adsorbent mass.

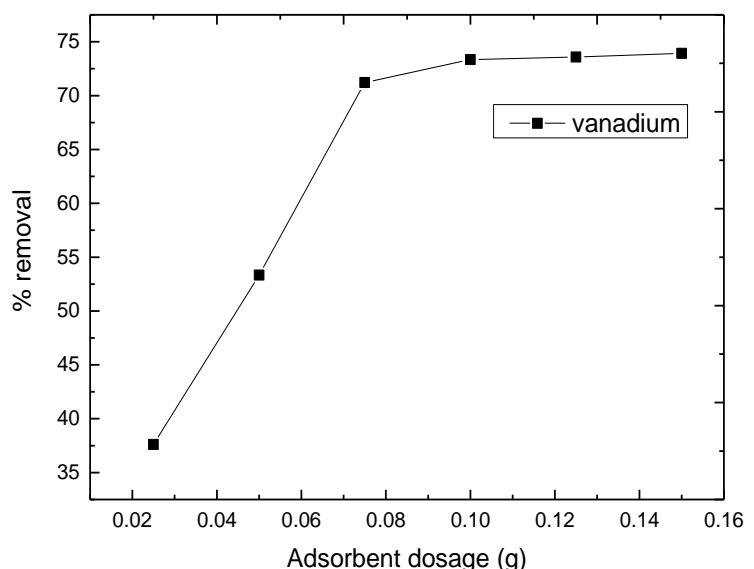

Fig. 2. Effect of adsorbent dosage on vanadium Adsorption (Temp. 298K, initial Conc. 100 ppm, pH 5 and duration 24h).

\section{Adsorption Isotherms}

The equilibrium data obtained from sorption experiments were analyzed using various isotherms in order to find a suitable model capable of describing the interaction between adsorbate and adsorbent for effective design of an adsorption process. The Langmuir and Freundlich adsorption isotherms equation were used. Furthermore the linear regression method was employed to fit these experimental data and to describe the model that fits best [19].

\section{Freundlich Isotherm}

The Freundlich isotherm assumes heterogeneous surface with a non-uniform distribution of heat on adsorption. The Freundlich isotherm is characterised by the following equation:

$$
q_{e}=K_{F} \times C_{e}^{1 / n}
$$

where $q_{e}$ is the equilibrium solid phase concentration ( $\mathrm{mg} / \mathrm{g}$ ), $C_{e}$ is the equilibrium liquid phase concentration $(\mathrm{mg} / \mathrm{L}), K_{F}$ and $n$ are indicative isotherm parameters of adsorption capacity and intensity respectively. The linear representation of the above equation is given by the following mathematical expression [20]:

$$
\ln q_{e}=\ln K_{F}+1 / n \times C_{e}
$$

Fig. 3 shows a plot of lnqe versus $\ln C_{e}$ and the value of the Freundlich parameters $K_{f}$ and $1 / n$ are presented in Table I Therefore, the adsorption of the vanadium molecules onto magnetic zeolite-polypyrrole composite cannot be well described by Freundlich isotherm model.

\section{E. Langmuir Isotherm}

The Langmuir isotherm assumes that adsorption takes place at specific homogenous sites within the adsorbent. The isotherm equation is given as:

$$
q_{e}=\frac{X_{m} K C_{e}}{\left(1+K C_{e}\right)}
$$

where $K$ and $X_{m}$ are the Langmuir constants related to the adsorption capacity and energy adsorption respectively. The linear representation is as follows:

$$
C_{e} / q_{e}=\left(1 / X_{m}\right) \times C_{e}+\frac{1}{K \times X_{m}}
$$

Fig. 4 illustrates a typical graphical representation of the linearized Langmuir adsorption isotherm. The values of the Langmuir parameters, $X_{m}, K$ and $R^{2}$ extracted from the plot are presented in Table I. From Table I the Langmuir isotherm parameters $X_{m}$ which measures the monolayer capacity of the sorbent material was found to $57.803 \mathrm{mg} / \mathrm{g}$. When comparing the correlation coefficient values obtained, Langmuir adsorption isotherm was a better fit for the batch equilibrium

\begin{tabular}{|c|c|c|c|}
\hline \multicolumn{4}{|c|}{ CR(VI) ADSORPTIONONTO MZ/PPY } \\
\hline Parameters & $\begin{array}{l}\text { Langmuir } \\
\text { constants }\end{array}$ & Parameters & $\begin{array}{l}\text { Freundlich } \\
\text { constants }\end{array}$ \\
\hline $\begin{array}{l}X_{m} \\
(\mathrm{mg} / \mathrm{g})\end{array}$ & 57.803 & $\begin{array}{l}K_{F} \\
(\mathrm{mg} / \mathrm{g})\end{array}$ & 20.725 \\
\hline $\begin{array}{l}K \\
(\mathrm{~L} / \mathrm{mg})\end{array}$ & 0.08831 & $n$ & 5.5617 \\
\hline$R^{2}$ & 0.99 & $R^{2}$ & 0.40 \\
\hline
\end{tabular}
data with higher correlation coefficient values of 0.99 for all cases.

TABLE I: LANGMUIR AND FREUNDLICH ISOTHERMS PARAMETERS FOR

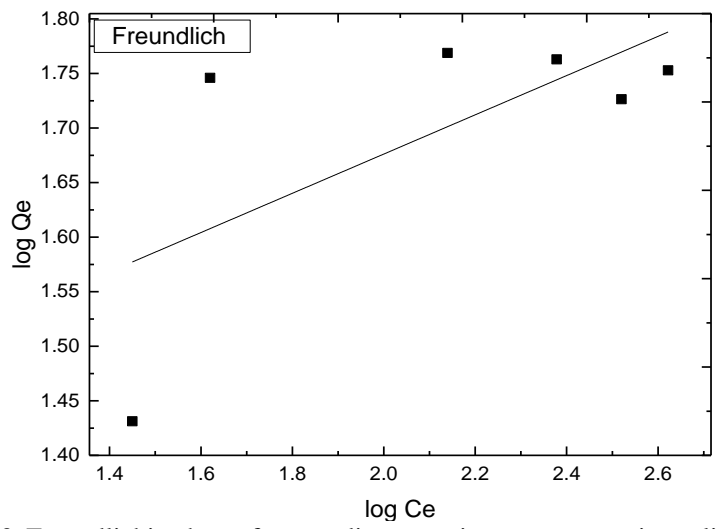

Fig. 3. Freundlichisotherm for vanadium sorption onto magnetic zeolite-ppy.

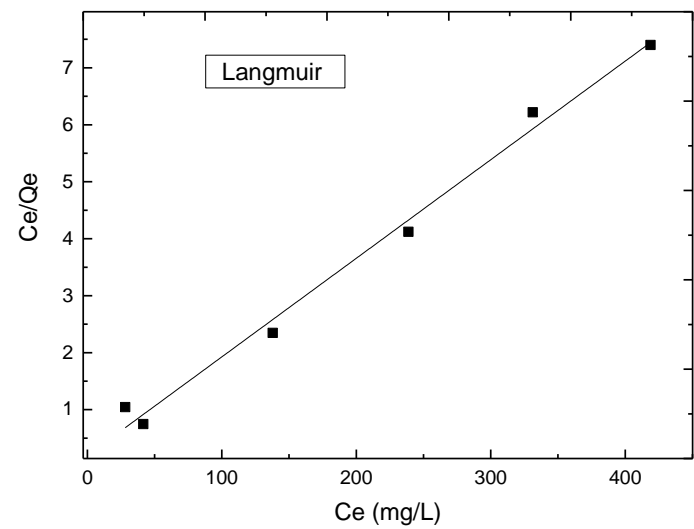

Fig. 4. Langmuirisotherm for vanadium sorption onto magnetic zeolite-ppy.

\section{CONCLUSION}

This work has established the adsorption of vanadium onto 
synthesized magnetic zeolite-polypyrrole. It was found that the magnitude of adsorption was primarily dependent of the solution initial $\mathrm{pH}$, the sorbent dosage. A $\mathrm{pH}$ of 5 was determined to be favorable for optimum removal of vanadium. This is consistent with literature expectation as the removal of vanadium from aqueous solutions is predicted by literature to be optimum at $\mathrm{pH}$ range of 4-6. An optimum media dosage was found to be $0.15 \mathrm{~g}$ of magnetic zeolite-polypyrrole which achieved $75 \%$ adsorption of vanadium from $100 \mathrm{ppm}$ initial concentration at $\mathrm{pH}$. The adsorption equilibrium was described better by Langmuir isotherm. The description of the equilibrium data by the the Langmuir isotherm was a demonstration of the homogeneous structure of the sorbent material and a confirmation that the adsorption of vanadium by magnetic zeolite-polypyrrole involves the attachment of only one layer of molecules to the surface (i.e. Monolayer adsorption). Because of the low cost of clinoptilolite and the relatively good sorption capacity achieved with magnetic zeolite-polypyrrole, this synthesized composite can be considered as a good prospective material for treatment of vanadium contaminated wastewaters.

\section{ACKNOWLEDGMENT}

The authors acknowledge the National Research Fund (NRF)-South Africa for the financial support provided, Tshwane University of Technology and University of South Africa for their financial contribution.

\section{REFERENCES}

[1] A. Naeem, P. Westerhoff, and S. Mustafa, "Vanadium removal by metal (hydr)oxide adsorbents," Water Research, vol. 41, pp. 1596-1602, Feb. 2007.

[2] T. S. Anirudhan and P. G. Radhakrishnan, "Adsorptive performance of an amine-functionalized poly(hydroxyethylmethacrylate)-grafted tamarind fruit shell for vanadium(V) removal from aqueous solutions,' Chemical Engineering Journal, vol. 165, pp. 142-150, Sep. 2010.

[3] Y. Fan, X. Wang, and M. Wang, "Separation and recovery of chromium and vanadium from vanadium-containing chromate solution by ion exchange," Hydrometallurgy, vol. 136, pp. 31-35, March 2013.

[4] W. Li, Y. Zhang, T. Liu, J. Huang, and Y. Wang, "Comparison of ion exchange and solvent extraction in recovering vanadium from sulfuric acid leach solutions of stone coal," Hydrometallurgy, vol. 131-132, pp. 1-7, Sep. 2013

[5] C. Pennesi, C. Totti, and F. Beolchini, "Removal of Vanadium(III) and Molybdenum(V) from Wastewater Using Posidoniaoceanica (Tracheophyta) Biomass," PLoS ONE, vol. 8, p. e76870, Oct. 2013.

[6] L. Zhang, X. Liu, W. Xia, and W. Zhang, "Preparation and characterization of chitosan-zirconium(IV) composite for adsorption of vanadium(V)," International Journal of Biological Macromolecules, vol. 64, Nov. 2014

[7] C. Namasivayam and D. Sangeetha, "Removal and recovery of vanadium(V) by adsorption onto $\mathrm{ZnCl}_{2}$ activated carbon: Kinetics and isotherms," Adsorption, vol. 12 , pp. 103-117, March 2006.

[8] A. Bhatnagar, A. K. Minocha, D. Pudasainee, H.-K. Chung, S.-H. Kim, H.-S. Kim, G. Lee, B. Min, and B.-H. Jeon, "Vanadium removal from water by waste metal sludge and cement immobilization," Chemical Engineering Journal, vol. 144, pp. 197-204, Jan. 2008.

[9] C. L. Peacock and D. M. Sherman, "Vanadium(V) adsorption onto goethite $(\alpha-\mathrm{FeOOH})$ at $\mathrm{pH} 1.5$ to 12 : a surface complexation model based on ab initio molecular geometries and EXAFS spectroscopy," Geochimica et Cosmochimica Acta, vol. 68, pp. 1723-173, April 2004

[10] T. Wang, Z. Cheng, B. Wang, and W. Ma, "The influence of vanadate in calcined $\mathrm{Mg} / \mathrm{Al}$ hydrotalcite synthesis on adsorption of vanadium (V) from aqueous solution," Chemical Engineering Journal, pp. 182-188, Feb. 2012

[11] M. Jansson-Charrier, E. Guibal, J. Roussy, B. Delanghe, P. Le Cloirec, "Vanadium (IV) sorption by chitosan: Kinetics and equilibrium," Water Research, vol. 30, pp. 465-475, Feb. 1996.

[12] A. Nakajima, "Electron spin resonance study on the vanadium adsorption by persimmon tannin gel," Talanta, vol. 57, pp. 537-544, Feb. 2002.
[13] M.-H. Liao, D. H. Chen, "Preparation and characterization of a novel magnetic nano-adsorbent," Journal of Materials Chemistry, vol. 12, pp. 3654-3659, Nov. 2002.

[14] M. Bhaumik, A. Maity, V. V. Srinivasu, and M. S. Onyango, "Enhanced removal of $\mathrm{Cr}(\mathrm{VI})$ from aqueous solution using polypyrrole/ $/ \mathrm{Fe}_{3} \mathrm{O}_{4}$ magnetic nanocomposite," Journal of Hazardous Materials, vol. 190, pp. 381-390, March 2011.

[15] M. Bhaumik, K. Setshedi, A. Maity, and M. S. Onyango, "Chromium(VI) removal from water using fixed bed column of polypyrrole/ $\mathrm{Fe}_{3} \mathrm{O}_{4}$ nanocomposite," Separation and Purification Technology, vol. 110, pp. 11-19, March 2013.

[16] H. Faghihian, M. Moayed, A. Firooz, and M. Iravani, "Evaluation of a new magnetic zeolite composite for removal of $\mathrm{Cs}^{+}$and $\mathrm{Sr}^{2+}$ from aqueous solutions: Kinetic, equilibrium and thermodynamic studies," Comptes Rendus Chimie, vol. 17, pp. 108-117, Feb. 2014

[17] C. D. Crans, "Fifteen Years of Dancing with Vanadium," Pure Applied Chemistry, vol. 77, pp. 1497-1527, 2005.

[18] C. D. Crans and S. T. Alan, "The Chemistry of Vanadium in Aqueous and Nonaqueous Solution," Vanadium Compounds, American Chemical Society, pp. 2-29, 1998.

[19] K. Z. Setshedi, M. Bhaumik, S. Songwane, M. S. Onyango, and A Maity, "Exfoliated polypyrrole-organically modified montmorillonite clay nanocomposite as a potential adsorbent for $\mathrm{Cr}(\mathrm{VI})$ removal," Chemical Engineering Journal, vol. 222, pp. 186-197, Feb 2013.

[20] N. Kocak, M. Sahin, and I. Gubbuk, "Synthesized of Sporopollenin-Immobilized Schiff Bases and Their Vanadium(IV) Sorption Studies," J Inorg Organomet Polym., vol. 22, pp. 852-859, July 2012.

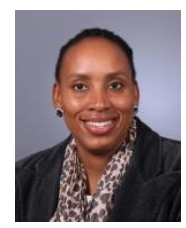

Nomcebo H. Mthombeni was born in South Africa in Kwa Zulu-Natal Province on the June 13, 1980. She obtained a national diploma in chemical engineering from Vaal University of Technology in 2004. In 2008, she obtained a B.Tech degree in chemical engineering from Tshwane University of Technology. She later obtained a master degree from Tshwane University of Technology in 2012. The thesis was titled "Experimental investigation and modelling of oligodynamic nanoparticle based filtration systems for water disinfection." She is currently doing her doctorate in chemical engineering at Tshwane University of Technology. She is a student member of WISA, SAICHE, ECSA.

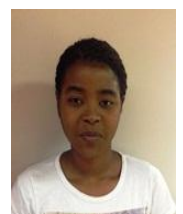

S. Mbakop was born in Ndjamena on November 13, 1988. She completed her primary and secondary schools in her country of origin Cameroon (Doula). She obtained the national diploma in chemical engineering in South Africa at the Institution of Tshwane University of Technology. She is currently busy completing her Baccaleureus Technologiae in chemical engineering.

She worked as a quality metallurgist at Mutanda Mining in the Democratic Republic of Congo for a year and decided to come back to South Africa in order to obtain a Baccaleureus Technologiae in chemical engineering. She is currently researching in the field of waste water treatment.

Mrs. Mbakop has completed her national diploma with cum laude and received an academic excellence award.

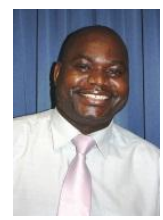

Maurice S. Onyango was born in Siaya County, Kenya in 1972. Onyango holds an honors degree in chemical and process engineering from Moi University, Kenya in 1997, master degree in environmental science and technology in Unesco-IHE, Delft, The Netherlands in 2001 and a doctorate degree in chemical engineering from Nagoya University, Japan in 2006.

He started his academic career as a junior lecturer in 1998. In 2007, he was appointed a senior lecturer at the Tshwane University of Technology (TUT) and rose to the rank of full professor in 2010. Currently, he is the head of the Department of Chemical, Metallurgical and Materials Engineering at TUT-Pretoria Campus. He has published widely in the areas of drinking water and wastewater treatment using adsorption technique. He has great interest in developing novel nanoadsorbents with enhanced capacity and kinetics for contaminants removal from water.

Prof. Onyango is a rated research by National Research Foundation (NRF) of South Africa. He has received several institutional awards in research and teaching. 